\title{
Carbon Footprints in the Sand: Marketing in the Age of Sustainability
}

\author{
Christopher Groening • J. Jeffrey Inman • \\ William T. Ross Jr.
}

Published online: 7 January 2014

(C) Springer Science+Business Media New York 2014

\begin{abstract}
A growing number of people wish to do no harm to the earth and leave a stable living environment for future generations. In response to the growing concern with carbon emissions' impact on the marketplace, this paper investigates the emerging field of sustainable development through the typical manner in which it is measured, carbon emissions. Firms are beginning to address this demand by reducing their carbon footprint, the carbon dioxide emissions created by a product throughout its life cycle. Simultaneously, carbon footprint labels have begun to appear on products in North America, Asia, and Europe. We examine both the potential impact of carbon footprint labels and their informational content from the perspectives of firms and consumers. Specifically, we lay the groundwork for future carbon footprint research by proposing how industry, firm, consumer, and label attributes affect firm action, content of carbon footprint labels, consumer preferences, and financial outcomes.
\end{abstract}

Keywords Sustainability · Carbon emissions $\cdot$ Carbon footprint $\cdot$ Product life cycle

Electronic supplementary material The online version of this article (doi:10.1007/s40547-013-0005-5) contains supplementary material, which is available to authorized users.

C. Groening $(\bowtie)$

Kent State University,

522 College of Business, Kent, OH 44242, USA

e-mail: cgroenin@kent.edu

J. J. Inman

Katz Graduate School of Business, University of Pittsburgh,

356 Mervis Hall, Pittsburgh, PA 15260, USA

e-mail: jinman@katz.pitt.edu

W. T. Ross Jr.

School of Business, University of Connecticut,

2100 Hillside Road Unit 1041, Storrs, CT 06269-1041, USA

e-mail: bill.ross@business.uconn.edu
In recent years, the consumer market has been transitioning to an era of sustainable development. Many corporations have come to realize that they are part of a larger entity and must help protect the common good [71]. For instance, General Electric has introduced a credit card to help consumers earn greenhouse gas emissions credits to reduce their personal carbon footprint [7], and Wal-Mart has initiated a Sustainability Index Consortium [83]. In fact, a new job category, professional pollution calculator, has emerged [84].

These are just a few examples of the advent of sustainable development, an emerging mainstream concept. They are representative of a larger trend of internal and external forces forcing social change by firms. Illustrating this trend, 45 of the 50 largest US companies included sustainability efforts in their 2008 annual reports or on their websites. The increasing concern with sustainability is not unwarranted; as the world's population has surpassed 7 billion, sustainability is justifiably of concern [25].

Sustainable development is defined as "development that meets the needs of the present without compromising the ability of future generations to meet their own needs"1 ([85] S3, A27, p. 16). Surprisingly, of corporate social responsibility (CSR) articles in the leading marketing journals ${ }^{2}$ from 2000 to 2013, only three mentioned sustainability. MacCannell [51] questioned whether ego-based consumption was sustainable and [87] examined consumers' choice of green products based on their attributes. We seek to stimulate attention to sustainability in the marketing literature by providing guidelines that can help to focus future research in this important area. Thus, we argue that it is crucial to study sustainability in a measurable form.

\footnotetext{
${ }^{1}$ At the macro-level, sustainability has been used to refer to a threepronged typology: environmental, social, and economic [65]; however in this paper, we focus on the environmental aspects of sustainability.

${ }^{2}$ Journal of Marketing, Journal of Marketing Research, Marketing Science, and Journal of Consumer Research
} 
One effective way to quantitatively convey a firm's level of sustainability is through a carbon footprint label. A product's carbon footprint represents the increase in carbon dioxide in the atmosphere resulting from the manufacture, transportation, usage, and disposal of that product. A smaller carbon footprint means a smaller increase in carbon dioxide and a lesser degree of harmful impact on the earth's sustainability. Consumers, in addition to firms, are increasingly familiar with the term "carbon footprint" through extended news coverage of climate change, multi-national treaties, and green investment [61].

Carbon footprint labeling is an efficient means for consumers to recognize the sustainability of a firm's products or services, and to compare them with those of other firms and their own preferences. Thus, how consumers and firms will be affected by the introduction of a universal carbon footprint label merits careful study. Similarly, a firm's attributes, industry, customer base, and carbon footprint label details are factors that would potentially impact a firm's reputation and financial outcomes. Research may reveal surprising or counterintuitive findings. For a parallel, consider nutritional information labels. Ippolito and Mathios [38] find that the advent of labels detailing food fat content coincided with reductions in fat consumption. Applying this outcome to carbon emissions suggests that carbon footprint labeling could increase consumers' level of attention to carbon emissions levels, potentially affecting their purchase decisions resulting in purchase of fewer product or products with lower carbon emission levels.

Specifically, in this paper we derive predictions regarding how consumers may respond to sustainability activities undertaken by firms. We base our propositions on the assumption that through a combination of industry adoption and government regulation and enforcement, carbon footprint labeling will become widespread and familiar to the average consumer in the near future. In Fig. 1, we provide a framework for our discussion. This research roadmap is based upon examination of related research in marketing, related business fields, news media, and websites of companies and carbon footprint organizations.

\section{Background}

\subsection{Carbon Footprint Labeling}

Until recently, carbon emissions were measured only at the national or firm level, which does not aid consumers in monitoring their personal carbon emissions levels. A carbon footprint label seeks to detail the emissions in the four stages of a product's lifetime, manufacture, transportation, usage, and disposal [15]. Because creating products with zero carbon emissions is often not possible, firms may offset some of their carbon emissions through means such as carbon sinks ${ }^{3}$ or living machines ${ }^{4}$ and report these on the label.

A carbon footprint label provides a comparison metric for consumers to consider a product's carbon emissions when making purchasing decisions. As yet, there is no universally agreed upon label. In order to facilitate our discussion, we present a hypothetical carbon footprint label that includes various carbon emissions and offsets from current and proposed systems. The label is adapted from existing labels (see the on-line appendix for all labels).

This illustrative label presents a product's carbon footprint using a single metric (e.g., grams) to provide common measurement for manufacturers and consumers. Carbon emission is displayed for each of the four product life cycle stages, the sum of the four stages, offsets (recycling, carbon sinks), the sum of the offsets, and net emissions (total carbon emission less total offsets). Emission data with different aggregate levels should assist those consumers who desire more detailed information, but mitigate information overload for those who do not. To facilitate consumer interpretation, we add an icon system so that consumers can compare carbon footprints across similar products. These footprint icons are scaled from 0 to 4 , incrementing in half footprints. Fewer footprint icons indicate a smaller footprint and a one word assessment (e.g., poor, average, or good) accompanies the icons. Comparison across products is useful because it facilitates consumer juxtaposition among goods with similar labels (e.g., nutritional data) [57].

Products vary in how the different stages of their life cycle contribute to their carbon footprint levels. A lawnmower's greatest carbon footprint impact is its gas emissions during usage. Bottled water has a high carbon footprint in the transportation stage because it is bulky and expensive to transport. Beef requires considerable resources to manufacture (to be raised to maturity). Finally, a television has high levels in each stage; high weight impacts transportation, a multi-year consumption of electricity impacts usage, and with few recyclable components, and hazardous materials that impact disposal.

\subsection{Current State of Sustainability and Carbon Footprint Labeling}

Consumer advocacy for sustainability and the ability to choose products based on their carbon footprint, is emerging already [37]. In response, a number of corporate, non-profit, and government entities have begun to address this issue (e.g., [16]). Similarly, several companies, including I.B.M., Nike, Coca-Cola, Google, and Dell, are investigating ways to reduce

\footnotetext{
${ }^{3}$ A carbon sink is a way to offset carbon consumption, such as planting trees, which both absorb carbon dioxide and emit oxygen, thus offsetting carbon dioxide emissions.

${ }^{4}$ A living machine is an organism that consumes material adverse to the health of the earth, such as arsenic.
} 
Fig. 1 Proposal framework

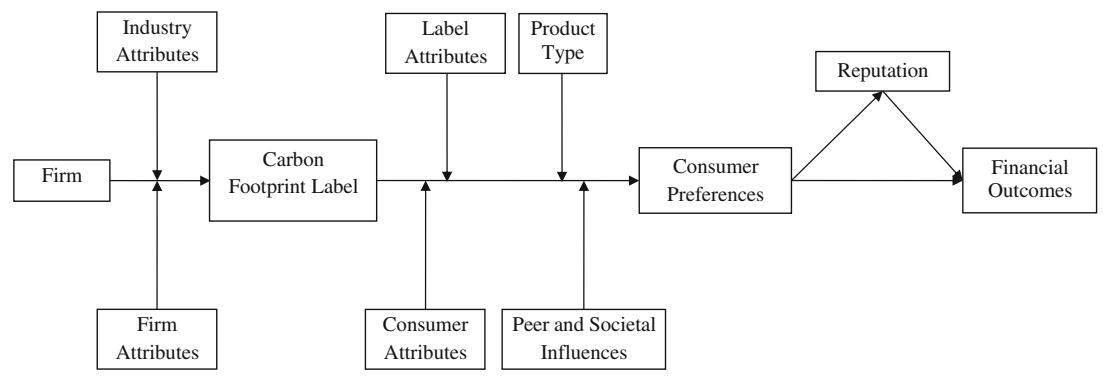

their carbon footprint and have joined forces to create a common carbon footprint label. Sapporo displays carbon emissions per can of beer from growing the ingredients, brewing them, manufacturing the can, and transporting it to distributors. Quaker Oats has shown carbon usage in cooking usage [79].

Groundwork for carbon footprint labeling arises from a combination of social trends, legislation, and product innovations. Fuel economy levels for cars are mandated. Recycling of plastic, metals, paper, and food products is now widespread. Energy efficient appliances are common, often qualifying for government rebates. Companies manufacture and distribute products with less packaging. Firms are cutting green-house gases used in manufacture and transportation; Empty Miles, for example, aims to reduce the miles that trucks travel empty [60]. In summary, technology, consumer demand, firm willingness, and government legislation will make carbon emission labeling a likelihood in the near future. This outcome increases the importance of understanding what leads firms and consumers to use carbon footprint labels.

\section{Proposition Development}

\subsection{Industry Characteristics}

Industry characteristics will affect firms' implementation of carbon footprint labeling, consumer responses to this labeling, and its financial outcomes. Banerjee et al [6] propose four industry level attributes that together define the natural business environment. We discuss two in this section: regulation (of carbon footprint labeling) and industry complexity as measured by concentration. A third, public concern, is discussed in a later section. Finally, we consider the fourth, managerial commitment, to be self-evident; increased managerial commitment will reduce carbon footprint levels.

To noticeably affect consumer behavior and industry practice, carbon footprint labeling should have what Kirmani and Rao [40] call the attributes of a strong signal. That is, the labeling should be salient, reduce information asymmetry between firms and their customers, and provide information clarity, payoff transparency, and credibility. Carbon footprint labels must be reliable and there should be negative consequences (e.g., fines) for their misuse. Industry standards usually lack an enforcement mechanism, which might compromise consumer faith in such a system [17]. In contrast, governmental regulation of carbon footprint labeling would have the authority to dictate uniformity and specificity across industries, states, and perhaps national borders [45]. As a result, consumers would be able to rely on clear, honest, and standardized criteria to verify manufacturer claims and make product comparisons and purchases [47]. The increased understanding, verifiability [43], and elimination of consumer confusion resulting from nutritional labeling was one of the primary impetuses for that legislation [26].

Existing labeling efforts suggest that voluntary industry labeling does not always produce the desired result for consumers. For example, organic labeling has minimal existing regulation associated with it, and critics argue that it misleads and confuses consumers and hampers interstate commerce [1]. Such controversies damage industry-led programs' credibility. The food industry-sponsored Smart Choice program that qualified Froot Loops, Cocoa Krispies, and Fudgsicle bars as "Smart Choices" drew the ire of the FDA [59]. Campbell [13] summarizes: "research suggests that government statutes are most effective in facilitating socially responsible corporate environmental behavior." Thus:

Proposition 1 Consumers will have more trust in a governmentally regulated carbon emission label than a voluntary industry-led one.

Note that mandating carbon emission labeling does not mandate specific goals for carbon levels, just that levels be reported. Thus, firms will be free to decide how much to reduce carbon emissions, but this transparency provided by carbon emission reporting will influence competitors' emissions. Thus, the level of industry competition may affect how much firms decrease their carbon emissions. Firms in more concentrated industries typically face lower levels of competition, and, when competition is present, it is likely to be less intense than in less concentrated industries (e.g., [76]). As competition increases, firms often must differentiate themselves and provide more choice for consumers (e.g., [22]). One method of differentiation may relate to carbon footprints. As competition increases, firms may expend more resources on carbon emission reduction activities to differentiate themselves. Once one firm in an industry 
differentiates itself by lowering its carbon footprint, other firms may feel compelled to match that level to counteract the original firm, thereby leading to a beneficial cycle of carbon emission reduction.

However, the decrease in carbon emissions as industry competition increases may not continue; competition may force firms to invest in responding to more pressing issues, such as customer satisfaction or firm efficiency. On the other hand, a less concentrated industry may comprise many small firms. While small firms may be more nimble than larger firms, they also have less slack resources [19]. Reducing carbon emissions to low levels requires access to slack resources. Thus firms in more highly concentrated industries may not have a need to reduce emissions whereas firms in less concentrated industries may not have the necessary resources to reduce emissions.

Proposition 2 Industry concentration will have an inverted Ushaped effect on the level of carbon emissions; firms in moderately concentrated industries will have less carbon emissions than firms in either low or high concentration industries.

\subsection{Firm Characteristics}

Firm-specific characteristics should affect carbon emissions. We focus on three firm characteristics relevant to sustainability: a firm's level of innovation, the level of consumer influence on a firm, and a firm's diversification through product portfolio breadth and geographic expansion. Carbon emission reduction requires technological innovation and consumer demand to become important. Firms, through their product breadth and market width, can affect its level and rate of reduction.

Innovation long has been considered a major function of a firm and a source of value creation [74]. It improves firm performance and lowers firm risk by facilitating the creation of competitive advantage through firm and product differentiation (e.g., [53]). Innovative firms are responsive to markets and customer needs [55] and thus should recognize the need to reduce emission levels. Firms with an innovative culture should be able to harness and direct this energy [41] toward lowering emission levels. In turn, a firm's brand equity may be improved through emissions reductions; consumers may feel that they are supporting an environmental cause by purchasing the product. Research indicates that CSR helps to create a reputation for reliability and honesty [53] and to increasing stakeholder perceptions of and identification with a firm [11]. Further, CSR also reduces firm risk [49], and we anticipate similar effects with carbon footprint labeling.

Empirical evidence suggests that firms benefit financially through the interaction of high levels of innovation, CSR, and customer satisfaction. The financial benefits of coupling high levels of customer satisfaction or CSR with high levels of innovation can occur indirectly through enhanced perceptions of firms [11], or directly by increasing Tobin's $q$ and stock return [50]. Thus:

Proposition 3 Firm technological innovation and carbon emission level will interact to affect firm performance; high innovation firms with low emissions will have higher financial performance and less financial risk than others.

Arora and Cason [4] find that firms with less contact with the general public are less likely to comply with voluntary EPA environmental programs. Greater consumer preference for lower carbon emissions should lead to increased firm emphasis on emission reduction goals. Similarly, firms that sell products to businesses that do not use these products to produce consumer goods may face less little pressure to reduce emissions. These "upstream" firms may find that their business customers place less importance on carbon emissions than attributes such as price or product specification adherence. If so, they will not be as concerned with emissions reduction and labeling as firms producing parts or raw materials for consumer goods producers.

Motivations to reduce carbon emissions may differ even among consumer goods firms. Some firms create and sell products directly to consumers, such as McDonalds, while other firms, such as P\&G, sell through an intermediary retailer, such as Wal-Mart. Firms that sell directly to consumers are more likely to feel the need to reduce their carbon footprint levels than those that do not. On the other hand, retailers such as Wal-Mart may be sufficiently powerful and willing to coerce suppliers to conform to their aims with respect to carbon footprint labeling. Thus, the degree to which our predictions are borne out with respect to proximity of connection to the consumer will be moderated by the aims and power of the retailer.

Proposition 4A The extent to which firms lower their carbon emissions will be moderated by the extent to which consumer reactions affect the firm. Firms that are less affected by consumer reaction will be less likely to lower their emissions.

Proposition 4B Firms that are more distant from customers (e.g., B2B firms) will expend fewer resources toward reducing carbon emissions than will firms that are directly involved with consumers (e.g., B2C firms).

Market size and market share should be relevant predictors of lower carbon emission levels for firm products. Szymanski et al. [78] find positive relationships between market share and a firm's quality, advertising expenditure, R\&D expenditure, and product line breadth. On the other hand, studies show that increased market share correlates with reduced customer satisfaction [2], lower prices, and suboptimal profits (e.g., [80]). 
Moreover, because large firms have more diverse customer bases than smaller firms, the pursuit of projects that do not appeal to a majority of customers may not be in a large firm's best interest. We argue that the same logic holds for carbon emissions.

Firms may achieve lower levels of emissions in other ways, such as through diversification and globalization. The improvement of intangible assets, in this case carbon emission knowledge, has been suggested as one of the main benefits that firms achieve through diversification and becoming multi-national (e.g., [30]). Firms with multiple product lines may be able to transfer the knowledge gained in reducing the carbon footprint for one product to its other products. In other words, a diversified firm should accumulate more knowledge of how to reduce carbon footprints than should a less diversified firm. Similarly, knowledge about carbon emissions management also can be developed by diversified firms via learning curve economies (e.g., [14]). Recent research shows that knowledge acquisition is a primary motivation and reason for success for diversification-based mergers (e.g., [75]).

The argument for increased carbon emission knowledge for globalized firms is similar to that for diversified firms because globalization is considered one type of diversification. Multinational firms face different regulations across the countries in which they do business, and may be able to apply insights from their experiences throughout their enterprise [88].

The relationship between firm diversification and the firm's ability to reduce carbon footprint levels may not be linear. However, the more a firm diversifies, the more complex it becomes, and managerial attention may become more divided (e.g., [66]). This increased complexity may limit how much the firm can decrease emission levels; managerial attention has been shown to be a key driver of innovation [86]. On the one hand, the more a firm diversifies the more likely it is to encounter external stakeholders who press the firm to improve its emission levels. On the other hand, such requests may not yield fruit because firms that are diversified tend to be less externally oriented [82].

One factor influencing motivation to respond to these stakeholders with respect to carbon emission reduction may be a firm's degree of market orientation. Firms that are more market oriented are more likely to take advantage of opportunities to assimilate knowledge and learn from their environment [42]. More importantly, market orientation focuses on both expressed and latent customer needs [73]. Since consumers are likely to value carbon emission level reduction, diversified market oriented firms should be more willing and able to outperform other firms in reducing their carbon footprint levels.

Proposition 5A Diversification, through both breadth and globalization, will have a U-shaped effect on the level of carbon emissions; moderately diversified firms will have lower levels of emissions than more or less diversified firms.

Proposition $5 B$ As a firm's level of market orientation increases, its product's carbon emissions will decrease.

Proposition 5C The U-shaped effect of diversification will be less pronounced for firms as their market orientation increases.

\subsection{Consumer Response to Carbon Footprint Levels}

Whether consumers prefer that Net Emissions level occur through reduction in actual emissions or offsets from carbon offset programs is important because, with limited resources, a company may have to choose between reducing actual emissions in the four life cycle stages of the product to reduce total emissions or investing in offset programs to reduce net emissions. We propose that offset-based emission reductions will influence consumer perceptions less than reducing actual emissions by an equivalent amount. Our prediction is based on consumers' willingness to expend cognitive effort in reading/using carbon footprint labels. Most consumers will focus on bottom-line net emissions rather than expend more cognitive effort and weigh the pros and cons of how the levels of emissions and offsets combine to create net emissions.

Research suggests that most consumers focus on less complicated options or simplifying heuristics in making decisions (e.g., [77]). For our label, this would mean examining the bottom line, net emissions, rather than any antecedent numbers in the calculation. Thus, in the scenario below, we expect that consumers will tend to view Product $A_{1}$ more favorably than Product $B_{1}$ because $A_{1}$ has a lower net emissions level than $B_{1}$, even though its actual emissions level is higher.

\begin{tabular}{lll}
\hline & Product $_{1}$ & Product $\mathrm{B}_{1}$ \\
Emissions & 120 & 100 \\
Offsets & 40 & 10 \\
Net Emissions & 80 & 90 \\
\hline
\end{tabular}

Proposition $6 A$ In comparing two similar products, consumers will weight Net Emissions (Emissions-Offsets) over Emissions alone.

The decision becomes more complex when a consumer faces a choice between products with equal levels of net emissions but different actual emission levels, recycling levels, and/or offset levels. In making this decision, the consumer must allocate weights to emissions and offsets. In the example below, we argue that Product $\mathrm{A}_{2}$ should be viewed more favorably than Product $\mathrm{B}_{2}$ or Product $\mathrm{C}_{2}$ because offsets, both in the form of recycling and carbon sinks, are uncertain 
and therefore may be more difficult to accept at $100 \%$ of their face value.

\begin{tabular}{llll}
\hline & $\begin{array}{l}\text { Product } \mathrm{A}_{2} \\
\text { Emissions }\end{array}$ & $\begin{array}{l}\text { Product } \mathrm{B}_{2} \\
120\end{array}$ & $\begin{array}{l}\text { Product } \mathrm{C}_{2} \\
\text { Offsets }\end{array}$ \\
$\quad 100$ & \\
Recycling & 10 & 10 & 50 \\
Carbon Sinks & 30 & 70 & 30 \\
Net Emissions & 80 & 80 & 80 \\
\hline
\end{tabular}

Proposition $6 B$ In comparing two similar products with the same Net Emissions, consumers will prefer lower Emissions over higher Offsets.

Finally, consider carbon sink offsets compared with recycling. Carbon sinks are harder to verify than recycling in which consumers can actively participate. Recycling depends on the consumer taking action to recycle. Yet, the trust consumers place in carbon sink calculations is influenced by unknowns - how long they will work, measurement accuracy, and whether the emission reduction actually is achieved [12]. Consumers have been found to distrust hard-to-verify claims on food labels [5]. Because consumers will tend to be more familiar with recycling than carbon sinks, consumers may prefer them due to a type of affect-based hedonic fluency model mere exposure effect presented by Fang et al. [24]. Thus, consumers may discount carbon sinks compared with recycling. In the scenario below, Product $A_{3}$ will be viewed more favorably than Product $B_{3}$.

\begin{tabular}{lll}
\hline & $\begin{array}{l}\text { Product } \mathrm{A}_{3} \\
100\end{array}$ & $\begin{array}{l}\text { Product } \mathrm{B}_{3} \\
100\end{array}$ \\
Emissions & & \\
Offsets & 20 & 10 \\
Recycling & 10 & 20 \\
Carbon Sinks & 70 & 70 \\
Net Emissions & & 70 \\
\hline
\end{tabular}

Proposition $6 C$ When comparing two similar products with the same Offsets, consumers will put more weight on Recycling than on Carbon Sinks.

Another important decision for the firm is whether to undertake an offset program itself or to rely on a third-party firm to manage it. From the firm's perspective, outsourcing the offset program may provide the most benefits. A firm specializing in offsets should be able to create and monitor an offset program at lower costs and with less risk. On the other hand, consumers may not view this decision the same way. Because consumers use different information as signals with which to infer firm motivations or product quality (e.g., [67]), they may view an outsourced offset program as an indication that the firm is not fully invested in carbon footprint reduction. Because product quality is signaled in part by reputation [21], it is reasonable to suggest that outsourcing carbon offset programs may signal lower product quality to some consumers.

Proposition $6 D$ When comparing two similar products with the same Offsets, consumers will prefer products from firms that manage their own Offset programs to those from firms that outsource their Offset programs.

\subsection{Consumer Characteristics and Their Response to Carbon} Footprint Labeling

Consumer characteristics - demographics, cognitive and personality factors - may affect how consumers react to carbon footprint labels and to their constituent parts. Prior research indicates that three common demographic characteristics affect ethical and food label choice; gender, age, and education; use of nutritional labels is higher among females, younger consumers, and the more highly educated [58]. Consumers who read nutritional labels should be more likely to read carbon footprint labels on the package, which should lead to greater awareness of carbon emissions. Because more highly educated consumers tend to be less price sensitive [32], they may be more likely to pay a premium for lower levels of carbon emissions.

Goolsby and Hunt [28] find that younger, more highly educated females score high on cognitive moral development, an indicator of socially responsible attitudes and behavior. Loe et al. [48], in their summary of empirical studies in ethical decision making, note that females and those who are more highly educated are more ethically sensitive. Thus, we predict:

Proposition $7 \mathrm{~A}$ Females will use carbon footprint labels to make product decisions more than males.

Proposition $7 B$ More highly educated consumers will use carbon footprint labels to make product decisions more than less educated consumers.

Proposition $7 C$ Younger consumers will use carbon footprint labels to make product decisions more than older consumers.

An individual difference variable that may play a prominent role in carbon emissions decision making is locus of control. Locus of control (LOC) is the degree to which a person believes that their behavior is internally motivated or controlled, contingent on their own actions or personal characteristics, versus external, beyond their control and a function of chance or the control of powerful others (e.g., [20]). Bierhoff et al. [10] find that people who are more likely to be altruistic have higher levels of internal LOC, while Singhapakdi and Vitell [72] find that high levels of internal LOC indicate increased moral identity. Cleveland et al. [20] find that an internal environmental LOC relates to recycling levels, while an external environmental LOC relates to 
exoneration of humans from responsibility for sustainability. These results suggest that consumers with higher internal LOC will focus more on carbon emissions, especially aspects of it in their control, such as recycling.

Proposition 8 The attention consumers pay to carbon emissions across the four stages of the product life cycle will be moderated by locus of control:

i. Consumers with higher levels of internal locus of control will pay more attention to the carbon footprint label than those with lower levels of internal locus of control.

ii. Consumers with higher levels of internal locus of control will place higher emphasis on the recycling part of the carbon footprint label compared to those with lower levels of internal locus of control.

The symbolic aspect of moral identity [3] and a general need for social approval should affect a consumer's decisions involving carbon footprints. Consumers generally are more involved in decisions about issues that are important to them, especially regarding their environmental consciousness [18], which is likely to trigger one's moral identity. The literature tells us that positive firm outcomes occur when there is a perceived fit regarding social issues between the firm's products and the individual consumer [9], but not when there is a disconnect between the firm's and customers' CSR values [69]. One reason for these findings may relate to a consumer's moral environmental involvement [3]. Moral identity is triggered for those who have a higher level of it when it becomes salient to the situation [68] such as when a fair trade label on coffee induces consumers with higher levels of ethical obligation to purchase more [64]. The existence of products with lower levels of carbon emissions compared to other products may trigger a consumer to demonstrate their higher level of symbolic moral identity and achieve a higher level of social approval [33].

Proposition 9A Consumers with higher levels of symbolic moral identity will place greater emphasis on carbon footprint labels when making product decisions than those with lower levels of symbolic moral identity.

At the basic level, prior research [50] implies that firms must exceed the expectations of their customers in order to achieve benefits from their CSR. Thus, consumers who desire lower carbon footprints will place a higher weight on carbon footprint levels. Disconfirmation in expectations also may disproportionally affect those firms that consumers perceive to be more moral. For example, Ben and Jerry's is known as a firm that has a goal of improving the quality of life locally (using local farmers when possible), nationally (sustainable forestry for paper packaging), and internationally (some profits from Rainforest Crunch were reinvested to preserve rainforests). Customers may therefore expect such firms to have higher levels of carbon footprint reduction. Thus, these firms may face higher penalties for greater carbon footprints compared with firms for which consumers have no prior expectations regarding carbon footprint levels. In addition, these same firms may have to greatly exceed the industry average before they achieve any benefits from consumers.

Proposition $9 B$ Consumers' prior expectations of the producer's carbon emissions will moderate the effect of the perception of a product's emission level on their purchase decision; a product with the same level of carbon emissions will be preferred more if the customer has low expectations than if the customer has high expectations.

Similar to social approval is the effect that peers may have on a carbon footprint label choice. Griskevicius et al. [29] discuss at length the unconscious copying behavior of humans in a sustainability context. Their examples consist of normative social behavior, where the desired behavior is influenced by notifying the decision maker of the level of positive societal group behavior in areas such as energy usage [62] or hotel towel reuse [27]. Solely informing people of sustainability issues seems to have little influence on behavior (e.g., [31]), however peers within a group can positively or negatively affect another individual's use of carbon footprint labels. Group adaptation increases trust [44] which should increase faith in offsets. Thus, group adoption of carbon footprint labels should increase faith in more questionable parts of the label, such as carbon sinks, moderating proposition $6 \mathrm{C}$.

Cultural group also should have a significant effect on carbon footprint label adoption. Collectivist cultures have tight bonds, and the members look after the interests of the group as a whole [35]. Such cultures have an increased interest in sustainability [46]. Yet, we reason that because of the high, initial level of attention this implies for carbon footprint labels in a collectivist culture, the influence of a pro-sustainability sub-group within the collectivist culture may not be as significant compared to a similar group in a more individualistic culture.

Another moderating influence on the role of peer influence in carbon emissions adoption is a group's socio-economic status. Clearly, price should matter more to low-income groups, but how will economic disadvantage affect the response to carbon labels? Economically disadvantaged groups may not find sustainability as relevant to them as other issues [52]. Thus, the overall importance of societal pressure should be less for more economically disadvantaged groups.

Proposition 10A The greater the amount of attention one's peers pay to carbon emissions the more the individual will pay attention to carbon emissions. 
Proposition $10 \mathrm{~B}$ Collectivist cultures will pay more attention to carbon emissions than individualist cultures.

Proposition 10C Group adoption of carbon footprint labels will moderate belief in the efficacy of carbon sinks. As group adoption of carbon footprint labels increases, so will the emphasis placed on carbon sinks.

Proposition 10D Cultural style will moderate the relationship between peer influence and attention paid to carbon emissions labels. As societal collectivism increases the influence of a peer group will decrease.

Proposition 10E The economic level of a group will moderate the relationship between peer influence and attention paid to carbon emissions labels. As the level of economic disadvantage increases the influence of a peer group will decrease.

An additional influence on attention to a carbon emission label may be the intended use of the product. Hedonic or experiential purchases are more tempting than utilitarian or functional, economic based purchases [8]. Since utilitarian purchases focus on product usage, the more utilitarian a product is the more attention will be paid to the usage stage of a carbon footprint label.

Proposition 11 The usage part of the carbon footprint label will carry more weight for utilitarian than hedonic products.

Frequently purchased products are usually chosen using simple choice heuristics, producing quick decisions [36]. Thus, carbon footprint labels on frequently purchased products are likely to play less of a role in the decision making process with frequently purchased products.

Proposition 12 As purchase frequency increases the carbon footprint label will play less of a role in product choice.

\subsection{Carbon Footprint Reduction and Firm Performance}

In theory it may seem beneficial for firms to reduce the carbon footprints of their products. For example, when positive health and nutritional information increases, purchase intentions also increase [43], which in turn increases actual purchases [70]. Perhaps more importantly, evidence suggests that nutritional labels increase the attention paid to nutritional aspects of food [5]. Translating these findings to carbon emission labeling, we would expect that labeling increases awareness of carbon emissions and their negative impact on the environment, while at the same time increasing purchase intentions and actual purchases for low emission products. However, the relationship between carbon footprint level reduction and increases in firm revenue may be nonlinear. That is, firms may see diminishing returns from sustainability investments in terms both of customer perceptions and financial returns. Customer satisfaction researchers have found a negative quadratic relationship between customer satisfaction and accounting measures [39], and between corporate reputation and price premiums [63]. Ittner and Larcker [39] report an increase in customer retention rate at a customer satisfaction score of about 67 , but no further increase for scores above 70 . In terms of carbon footprint labels, a greater increase in revenue may be achieved by improving a product's rating from the industry norm to one standard deviation higher than the industry norm, rather than improving it to two standard deviations above the industry norm. If this non-linear relationship holds for carbon emission levels, the increased revenue associated with emission reduction may at some point be outweighed by the increased costs required to further reduce emissions. In addition, investors may balk at increasing investment in lowering emissions levels.

Proposition 13A Carbon footprint improvements beyond the product category average will produce positive but diminishing marginal financial returns.

An important question is how firms' financial outcomes will change as their carbon footprint becomes worse than the industry average (p. 25 [34]). We argue that firms will experience increasing marginal negative financial returns and customer perception of the firm as their products' carbon footprints further exceed the industry mean. Eventually, though, a plateau will be reached where customer perception will not drop any further due to carbon emissions levels, producing an S-shaped response function.

In many choice decisions, loss aversion dictates that the risk of losses outweighs equivalent gains (e.g., [81]). Thus, higher levels of carbon emissions than the industry average should weigh more heavily than achieving emissions (gains) below the industry average. However, higher levels of carbon emissions should be weighted even more heavily. For example, Mittal et al. [54] find that negative performance has a disproportionate effect on customer satisfaction, and, more importantly, that while there is diminishing sensitivity to positive performance, this is not true for negative performance. Luo and Bhattacharya [50], in their study of CSR, customer satisfaction, and corporate ability, find that when firm innovation and CSR are disconnected, firm revenue suffers more. In investigating nutritional labeling, researchers found that consumers pay more attention care more about negative than positive nutrition attributes (e.g., [5]).

Proposition $13 B$ Increases of carbon footprint levels above the product category average will produce asymmetric (accelerated) negative financial effects before flattening out (S-Shaped response) 


\subsection{Testing Propositions}

The thrust of this paper is conceptual in nature, so empirical testing of the propositions is an important next step. To assist researchers in testing our propositions, we present possible approaches and methodologies in Table 1. Most of the propositions (P1-P5) that focus on industry and firm attributes can best be tested using secondary data sources. The propositions

Table 1 Suggestions to test propositions

\begin{tabular}{ll}
\hline$\# \quad$ Summary of proposition \\
\hline $1 \quad \begin{array}{c}\text { Consumers will prefer carbon emission that have government } \\
\text { regulation }\end{array}$
\end{tabular}

(1)

Moderately competitive industries will have the lowest level of carbon emissions

Firms with high levels of technological innovation and low levels of carbon emissions will have the highest levels of success and lowest levels of risk

$\mathrm{B} 2 \mathrm{~B}$ firms and B2C firms further from customers will expend fewer resources on reducing carbon emissions than $\mathrm{B} 2 \mathrm{C}$ firms, and B2C firms closer to customers

A) Moderately diversified firms will have the lowest levels of carbon emissions, C) but this effect will be less pronounced as market orientation increases

B) Higher market orientation $=$ decreased emissions

Net emissions (Emissions - Offsets) $>$ Emissions alone

Lower emissions $>$ Higher offsets (Recycling and carbon sinks)

Recycling $>$ Carbon sinks

Manage own offset programs $>$ Outsource offset programs

Females will use carbon footprint labels more

Consumers with higher levels of education will use carbon footprint labels more

Younger consumers will use carbon footprint labels more

Consumers with higher levels of internal locus of control will place higher emphasis on recycling

ii. Consumers with higher levels of external locus of control will pay less attention to the carbon footprint label

Consumers with higher levels of moral identity will place higher emphasis on carbon footprint labels (moderated by their expectations of a firm's carbon emission level)

A) Peers and B) collectivist societies positively affect carbon emission attention and C) efficacy of carbon sinks D\&E) Collectivism \& economics moderate peer influence

Usage stage matters more for utilitarian v. hedonic

Purchase frequency diminishes footprint importance

Improvements above the product category average will produce positive but diminishing financial returns

Increases below the product category average will produce accelerated financial losses
Testing methodology

1) Natural exp. - Compare consumer sentiment across countries with different carbon legislation

2) Study - Present half of subjects with scenario where industry implements labeling, and the other subjects where the government regulates labeling

Natural experiment - Compare firms industry concentration with carbon levels

Natural experiment - Interact firms R\&D with carbon levels. Use measures of financial risk and return as outcome measures

Natural experiment - Compare levels of resources as a percentage of sales and income between B2B, B2C, service and goods firms

Natural experiment - Compare firms diversification with carbon levels Combine with a survey measuring market orientation.

Study - Subjects rate identical products, but with varying Net Emissions, Emissions, and Offsets

Study - Subjects rate identical products and Net Emissions, but vary Emissions and Offsets

Study - Subjects rate identical products with same total Offsets, vary Recycling and Carbon Sinks

Study - Rate identical products with same total Offsets, vary whether Offset program is outsourced

Natural experiment - Compare choice behavior between alternatives after introduction of carbon emission information.

1) Study - Conjoint analysis. Collect data on different product attributes including carbon emissions and demographic information

2) In store experiment - View how consumers handle products to see whether they actually view the carbon footprint label

In store experiment - View how consumers handle products to see whether they actually view the carbon footprint label.

Study - Conjoint analysis. Collect data on different product attributes including carbon emissions and moral identity. Manipulate moral identity.

Cross cultural study - Use ideas similar to those for Props 7A-C

Study - Vary levels of carbon in Usage stage for several each of utilitarian and hedonic products

Scanner data exp. - Examine purchases to see the correlation between frequency and carbon level

Study - Assess participants' preference, intention to purchase, and actual purchase rates of products with varying carbon footprint levels 
(P6-P13), that focus on label and consumer attributes, lend themselves to laboratory studies, scanner data, and possibly surveys. One challenge with testing our propositions is the current lack of information about carbon emissions levels, which we view as an opportunity rather than an obstacle. As the marketplace adopts carbon footprint labeling, researchers will be better able to trace changing consumer attitudes and purchase behavior. In other words, the time is ripe for natural, quasi-experimental field studies in the area of carbon labeling, as Moorman et al. [56] did with the Nutrition Labeling and Education Act of 1990.

\section{Conclusion}

As more of the world's population becomes concerned with protecting the environment, the relevance of sustainable development to firm management will increase. Our paper posits one measurable aspect of sustainability, universal carbon footprint labeling, and examines the impact on firms and consumers. We have analyzed industry, firm, consumer and label attributes affecting firm action, content of carbon footprint labels, consumer preferences, and finally financial outcomes. We hope that the research community will build upon and test our propositions, and that managers will utilize insights from our paper.

First, managers should recognize that carbon footprint labeling is not just a benefit to society but can be used to improve the firm's competitive position. Managers should mobilize resources to prepare for this eventuality. Second, practitioners need to consider how consumers will interpret the information displayed on the carbon footprint label. As with other managerial decisions, cost efficiency must be balanced with understanding consumers' response and its firm profitability implications. Being better than the industry average in terms of carbon emissions is probably preferable, but, at some point, emissions reductions may have diminishing returns. On the other hand, falling below the industry average may have negative financial consequences for a firm. Because brand credibility increases the likelihood of inclusion in consideration sets [23], there may be multiple benefits to firms with low emissions during the consumer decision and purchase making process.

Third, any carbon labeling system must account for carbon emitted during the product's entire life cycle. If consumers place more weight on the parts of the product life cycle that are more within their control, firms may wish to emphasize usage and disposal, although the firm has the most control over manufacture and transportation, which may be valued by other consumers. Yet, it may be difficult to reduce carbon emissions during some or all of the life-stages of many products, so firms may opt to use offsets in these cases. Consumers may view these programs with varying degrees of skepticism, thus firms should apply discretion in managing these programs.

Fourth, management should recognize how carbon footprint labeling will interact with other firm and industry characteristics such as advertising, innovation, competition, and product category. Finally, firms should be aware of possible changes in consumption habits. For instance, more consumers may switch to filtering their own water rather than buying bottled water which comes with a large transportation carbon footprint. Likewise, when consumers recognize the high levels of carbon to create one pound of beef, they may eat less meat in general or choose pork, which has a much lower carbon footprint.

Our paper has not touched on every aspect of sustainability. For example, although we addressed several customer characteristics, others, such as guilt, may also have an effect. Additionally, we did not discuss other issues, such as legislated market-based approaches or other relevant environmental issues such as water usage, deforestation, and nitrogen emission. These issues may be included in future product labeling, but the underlying propositions should remain applicable. We hope our manuscript prompts research and dialogue regarding an issue that will significantly affect the field of marketing for years to come.

\section{References}

1. Amaditz KC (1997) The Organic Foods Production Act of 1990 and Its Impending Regulations: A Big Zero for Organic Food? Food and Drug Law Journal 52:527-59

2. Anderson EW, Fornell C, Lehmann DR (1994) Customer Satisfaction, Market Share, and Profitability: Findings from Sweden. J Mark 58(3):53-66

3. Aquino KF, Americus II Reed (2002) The Self-Importance of Moral Identity. Journal of Personality \& Social Psychology 83(6): 1423-40

4. Arora S, Cason TN (1996) Why do Firms Volunteer to Exceed Environmental Regulations? Understanding Participation in EPA's 33/50 Program. Land Econ 72(4):413-32

5. Balasubramanian SK, Cole C (2002) Consumers' Search and Use of Nutrition Information: The Challenge and Promise of the Nutrition Labeling and Education Act. J Mark 66(3):112-27

6. Banerjee SB, Iyer ES, Kashyap RK (2003) Corporate Environmentalism: Antecedents and Influence of Industry Type. J Mark 67(2):106-22

7. Barr C (2008) "GE to Cut Water Use by $20 \%$," CNN.com.

8. Baumeister RF (2002) Yielding to Temptation: Self-Control Failure, Impulsive Purchasing, and Consumer Behavior. J Consum Res 28: 670-76

9. Becker-Olsen KL, Andrew Cudmore B, Hill RP (2006) The Impact of Perceived Corporate Social Responsibility on Consumer Behavior. J Bus Res 59(1):46-53

10. Bierhoff HW, Klein R, Kramp P (1991) Evidence for the Altruistic Personality from Data on Accident Research. J Pers 59(2):263-80

11. Brown TJ, Dacin PA (1997) The Company and the Product: Corporate Associations and Consumer Product Responses. J Mark 61(1):68-84 
12. Bumpus AG, Liverman DM (2008) Accumulation by Decarbonization and the Governance of Carbon Offsets. Econ Geogr 84(2):127-55

13. Campbell JL (2007) Why Would Corporations Behave in Socially Responsible Ways? An Institutional Theory of Corporate Social Responsibility. Acad Manag Rev 32(3):946-67

14. Capron L (1999) The Long-Term Performance of Horizontal Acquisitions. Strateg Manag J 20(11):987-1018

15. Carbon Trust (2013) "Carbon Footprint Labels from the Carbon Trust," (accessed 11/16/13, 2013), [available at http://www. carbontrust.com/client-services/footprinting/footprint-certification/ carbon-footprint-label].

16. Carbonfund.org (2013) "CarbonFree ${ }^{\mathrm{TM}}$ Product Certification Carbon Footprint Protocol,” [available at http://www.carbonfund.org/site/ uploads/Product_Certification_Protocol_-_2007-07.pdf].

17. Caswell JA, Padberg DI (1992) Toward a More Comprehensive Theory of Food Labels. Am J Agric Econ 74(2):460-68

18. Chan RYK, Leung TKP, Wang YH (2006) The Effectiveness of Environmental Claims for Services Advertising. J Serv Mark 20(4): 233-50

19. Chen M-J, Hambrick DC (1995) Speed, Stealth, and Selective Attack: How Small Firms Differ from Large Firms in Competitive Behavior. Acad Manag J 38(2):453-82

20. Cleveland M, Kalamas M, Laroche M (2005) Shades of Green: Linking Environmental Locus of Control and Pro-Environmental Behaviors. The Journal of Consumer Marketing 22(4/5):198-212

21. Dawar N, Parker P (1994) Marketing Universals: Consumers' Use of Brand Name, Price, Physical Appearance, and Retailer Reputation as Signals of Product Quality. J Mark 58(2):81-95

22. Day GS and Montgomery DB (1999) "Charting New Directions for Marketing," Journal of Marketing, 63 (Special Issue: Fundamental Issues and Directions for Marketing), 3-13

23. Erdem T, Swait J (2004) Brand Credibility, Brand Consideration, and Choice. J Consum Res 31(1):191-98

24. Fang X, Singh S, Ahluwalia R (2007) An Examination of Different Explanations for the Mere Exposure Effect. J Consum Res 34(1):97103

25. Foley JA (2011) Can We Feed The Wrold \& Sustain The Planet? Sci Am 305(5):60-65

26. French WA, Barksdale HC (1974) Food Labeling Regulations: Efforts toward Full Disclosure. J Mark 38(3):14-19

27. Goldstein NJ, Cialdini RB, Griskevicius V (2008) A Room with a Viewpoint: Using Social Norms to Motivate Environmental Conservation in Hotels. J Consum Res 35:472-82

28. Goolsby JR, Hunt SD (1992) Cognitive Moral Development and Marketing. J Mark 56(1):55-68

29. Griskevicius V, Cant SM, van Vugt M (2012) The Evolutionary Bases for Sustainable Behavior: Implications for Marketing, Policy, and Social Entrepreneurship. Journal of Public Policy \& Marketing 31(1):115-28

30. Gupta AK, Govindarajan V (2000) Knowledge Flows within Multinational Corporations. Strateg Manag J 21(4):473-96

31. Connell H, Kim Y, Kozar JM (2012) Social Normative Influence: An Exploratory Study Investigating its Effectiveness in Increasing Engagement in Sustainable Apparel-Purchasing Behaviors. Journal of Global Fashion Marketing 3(4):172-79

32. Hoch SJ, Kim B-D, Montgomery AL, Rossi PE (1995) Determinants of Store-Level Price Elasticity. J Mark Res 32(1):17-29

33. Hoeffler S, Keller KL (2002) Building Brand Equity through Corporate Societal Marketing. Journal of Public Policy \& Marketing 21(1):78-89

34. Hoffman AJ, Woody JG (2008) Climate Change: What's Your Business Strategy? Harvard Business Press, Boston, Massachusetts

35. Hofstede G (1983) The Cultural Relativity of Organizational Practices and Theories. J Int Bus Stud 14(2):75-89

36. Hoyer WD (1984) An Examination of Consumer Decision Making for a Common Repeat Purchase Product. J Consum Res 11(3):822-29
37. Information Resources Inc. (2008), "IRI Study Finds Sustainability an Emerging Key to Product and Store Selection." Chicago.

38. Ippolito PM, Mathios AD (1994) Information, Policy, and the Sources of Fat and Cholesterol in the U.S. Diet. Journal of Public Policy \& Marketing 13(2):200-17

39. Ittner CD and Larcker DF (1998) "Are Nonfinancial Measures Leading Indicators of Financial Performance? An Analysis of Customer Satisfaction," Journal of Accounting Research, 36 (Supplement), 1-35.

40. Kirmani A, Rao AR (2000) No Pain, No Gain: A Critical Review of the Literature on Signaling Unobservable Product Quality. J Mark 64(2):66-79

41. Kitchell S (1995) Corporate Culture, Environmental Adaptation, and Innovation Adoption: A Qualitative/Quantitative Approach. J Acad Mark Sci 23(3):195-205

42. Kohli AK, Jaworski BJ (1990) Market Orientation: The Construct, Research Propositions, and Managerial Implications. J Mark 54(2): $1-18$

43. Kozup JC, Creyer EH, Burton S (2003) Making Healthful Food Choices: The Influence of Health Claims and Nutrition Information on Consumers' Evaluations of Packaged Food Products and Restaurant Menu Items. J Mark 67(2):19-34

44. Landy S and Menna R (2006) Early Internevtion with Multi-Risk Families: Paul H. Brookes Publishing Co.

45. Lathrop KL (1990) Pre-empting Apples with Oranges: Federal Regulation of Organic Food Labeling. Journal of Corporation Law $16: 885-930$

46. Lee K (2008) Opportunities for Green Marketing: Young Consumers. Mark Intell Plan 26(6):573-86

47. Levy AS (1995) "PHS Food Label Health Claims Focus Group Report: Executive Summary," Food and Drug Administration (Ed.). Center for Food Safety and Applied Nutrition.

48. Loe TW, Ferrell L, Mansfield P (2000) A Review of Empirical Studies Assessing Ethical Decision Making in Business. J Bus Ethics 25(3): 185-204

49. Luo X, Bhattacharya CB (2009) The Debate over Doing Good: Corporate Social Performance, Strategic Marketing Levers, and Firm-Idiosyncratic Risk. J Mark 73(6):193-213

50. Luo X, Bhattacharya CB (2006) Corporate Social Responsibility, Customer Satisfaction, and Market Value. J Mark 70(4):1-18

51. MacCannell D (2002) The Ego Factor in Tourism. J Consum Res 29(1):146-51

52. McGranahan G, Songsore J and Kjellen M (2002) "Sustainability, Poverty and Urban Environmental Transitions," in Sustainability the Environment and Urbanisation Cedric Pugh, ed.: Earthscan Publications Limited.

53. McWilliams A, Siegel D (2000) Corporate Social Responsibility and Financial Performance: Correlation or Misspecification? Strateg Manag J 21(5):603-09

54. Mittal V, Ross WT Jr, Baldasare PM (1998) The Asymmetric Impact of Negative and Positive Attribute-Level Performance on Overall Satisfaction and Repurchase Intentions. J Mark 62(1):33-47

55. Mizik N, Jacobson R (2003) Trading Off Between Value Creation and Value Appropriation: The Financial Implications of Shifts in Strategic Emphasis. J Mark 67(1):63-76

56. Moorman C, Rex D, Mela CF (2005) The Effect of Standardized Information on Firm Survival and Marketing Strategies. Mark Sci 24(2):263-74

57. Muller TE (1985) Structural Information Factors Which Stimulate the Use of Nutrition Information: A Field Experiment. J Mark Res 22(2): $143-57$

58. Neuhouser ML, Kristal AR, Ruth Patterson E (1999) Use of Food Nutrition Labels is Associated with Lower Fat Intake. J Am Diet Assoc 99(1):45-53

59. New York Times, The (2009) "For Your Health, Froot Loops," in Neuman, William. NY 
60. New York Times, The (2010) "Keeping Trucks Full, Coming and Going," in Belson, Ken. NY.

61. New York Times, The (2012) "With Carbon Dioxide Emissions at Record High, Worries on How to Slow Warming," in Justin Gillis and John M. Broder.

62. Nolan JM, Wesley Schultz P, Cialdini RB, Goldstein NJ, Griskevicius V (2008) Normative Social Influence is Underdetected. Personal Soc Psychol Bull 34(7):913-23

63. Obloj T, Obloj K (2006) Diminishing Returns from Reputation: Do Followers Have a Competitive Advantage? Corp Reput Rev 9(4): 213-24

64. Ozcaglar-Toulouse N, Shiu E, Shaw D (2006) In Search of Fair Trade: Ethical Consumer Decision Making in France. Int J Consum Stud 30(5):502-14

65. Porter ME, Kramer MR (2006) The Link between Competitive Advantage and Corporate Social Responsibility. Harv Bus Rev 84(12):78-91

66. Ramanujam V, Varadarajan P (1989) Research on Corporate Diversification: A Synthesis. Strateg Manag J 10(6):523-51

67. Rao AR, Lu Q, Ruekert R (1999) Signaling Unobservable Product Quality through a Brand Ally. J Mark Res 36(2):258-68

68. Reed A II (2004) Activating the Self-Importance of Consumer Selves: Exploring Identity Salience Effects on Judgments. J Consum Res 31(2):286-95

69. Sen S, Bhattacharya CB (2001) Does Doing Good Always Lead to Doing Better? Consumer Reactions to Corporate Social Responsibility. J Mark Res 38(2):225-43

70. Sheppard BH, Hartwick J, Warshaw PR (1988) The Theory of Reasoned Action: A Meta-Analysis of Past Research with Recommendations for Modifications and Future Research. J Consum Res 15(3):325-43

71. Sheth JN, Sethia NK, Srinivas S (2011) Mindful Consumption: A Customer-Centric Approach to Sustainability. J Acad Mark Sci 39(1):21-39

72. Singhapakdi A, Vitell SJ (1991) Research Note: Selected Factors Influencing Marketers' Deontological Norms. J Acad Mark Sci 19: $37-42$

73. Slater SF, Narver JC (1998) Customer-Led and Market-Oriented: Let's Not Confuse the Two. Strateg Manag J 19(10):1001-06
74. Slater SF, Narver JC (1994) Market Orientation, Customer Value, and Superior Performance. Business Horizons 37(2):22-28

75. Sorescu A, Chandy R, Prabhu J (2007) Why Some Acquisitions Do Better than Others: Product Capital as a Driver of Long-term Stock Returns. J Mark Res 44(1):55-72

76. Steenkamp J-BEM, Nijs VR, Hanssens DM, Dekimpe MG (2005) Competitive Reactions to Advertising and Promotion Attacks. Mark Sci 24(1):35-54

77. Swait J, Adamowicz W (2001) The Influence of Task Complexity on Consumer Choice: A Latent Class Model of Decision Strategy Switching. J Consum Res 28(1):135-48

78. Szymanski DM, Bharadwaj SG, Rajan Varadarjan P (1993) An Analysis of the Market Share-Profitability Relationship. J Mark 57:1-18

79. Telegraph (2009) "New Label to Show How Environmentally Friendly Your Porridge Is," (accessed 7/6/09, 2009), [available at http://www.telegraph.co.uk/].

80. Tellis GJ (1989) The Impact of Corporate Size and Strategy on Competitive Pricing. Strateg Manag J 10(6):569-85

81. Tversky A, Kahneman D (1974) Judgment under Uncertainty: Heuristics and Biases. Science 185(4157):1124-31

82. Varadarajan PR, Jayachandran S, Chris White J (2001) Strategic Interdependence in Organizations: Deconglomeration and Marketing Strategy. J Mark 65(1):15-28

83. Wal-Mart (2013) "Sustainability Index," (accessed 11/16/13, 2013), [available at http://corporate.walmart.com/global-responsibility/ environment-sustainability/sustainability-index].

84. Wall Street Journal, The (2009) "Hot Job: Calculating Products' Pollution," in Ann Campoy. NY.

85. World Commission on Environment and Development (1987), "Our Common Future," United Nations [available at http://www.undocuments.net/our-common-future.pdf].

86. Yadav MS, Prabhu JC, Chandy RK (2007) Managing the Future: CEO Attention and Innovation Outcomes. J Mark 71(4):84-101

87. Ying-Ching L, Chang C-CA (2012) Double Standard: The Role of Environmental Consciousness in Green Product Usage. J Mark 76(5):125-34

88. Zahra SA, Duane Ireland R, Hitt MA (2000) International Expansion by New Venture Firms: International Diversity, Mode of Market Entry, Technological Learning, and Performance. Acad Manag J 43(5):925-50 